\title{
The Design of Integrated Logistics Management System of an Industrial Company
}

\author{
Martin Hart $^{1, *}$ \\ ${ }^{1}$ Tomas Bata University in Zlin, Faculty of Logistics and Crisis Management, Logistics Department, \\ T.G. Masaryka 5555, 76001 Zlin, Czech Republic
}

\begin{abstract}
In the contemporary global business markets environment, when the business markets are getting more and more commercial, there are growing demand for effective management of material flows. The effectivity and effectiveness of planning, management and control the material flows across an industrial company and its distribution networks, represents one of the main pillar regarding the high level of competitive advantage within the frame of supply chains. Thus, the company information management system design should have also included a module of integrated logistics management system to ensure required level of material flow management effectivity and effectiveness. The article deals with brief description of the issues on company management, company information management systems and logistics management. Further it's stated the methodology to created integrated logistics management system, which is containing the methodics to design logistics management sub-systems of purchasing, manufacturing, distribution and reverse material flows. The essential methodics of the stated methodology is the methodics to create independent demand forecasting sub-system.
\end{abstract}

\section{Introduction}

Global business environment and business markets commercialisation enhance by distinctive manner the requirements putting on industrial companies within the context of competitive advantage high level achievement and living environment protection. Wide range of the products and services in the industrial or business markets is the factor to seek the ways for costs reduction, which are connected with their production or distribution. The one of the ways, how to reach mentioned costs reduction, which are related to the products manufacturing, it's the design or the optimization of the company's management systems, which embody the high level of effectivity and effectiveness. That's the one of the prospective ways, how to increase competitive advantage level in the current markets. The one of the main modules of the company's information management systems in the contemporary turbulent global business environment is the integrated logistics management system. The effectivity and the effectiveness of the planning, management and control, the material flows of the industrial companies or the entire supply chains, represents important

* Corresponding author: hart@utb.cz 
potential source to reach the high level of competitive strength in the up-to-date commercialized business markets.

The integrated logistics management system of an industrial company should be formed by the sub-systems of the planning, management and control, the particular functional areas. Those functional levels, namely purchasing, manufacturing, distribution and reverse material flows, are crosscut by the material flows. Well, the design or optimization of the company's information management systems or more precisely the design of the integrated logistics management systems is the field, which should be taken into account by all the nodes or the elements of the contemporary supply chains.

\section{Enterprise management and enterprise information system}

The success and the prosperity of the current enterprises are given by the high-quality company's management. The enterprise management is constituted by the effective design and the cross connection of the particular company's functional fields. The essential functional fields of the company are:

- research and development,

- purchasing,

- manufacturing,

- logistics - distribution,

- finance \& accounting,

- sales \& marketing,

- human resources.

The companies or the organisations of the particular industries, at present time of the global dynamic market environment, are still more realising the importance of the company management quality - stability and flexibility. This fact is not just from the company's IS/IT point of view, but it's especially from the first rate managerial decisions making process point of view [1].

The single functional levels of the company it's necessary, in current dynamic market environment, to take as the systems [2]. These systems should have been composed in the sense to reach required level of stability, flexibility, resilience and living environment protection. Thus, firstly there are created particular functional areas - the systems and the processes which are running in them. Subsequently the functional areas are integrated thru the process management principles including the planning, management and control of the all flows, which are streaming in the internal or the external company's supply chains [3].

The company's management includes the application of the exact methods developed for the analysis and synthesis given processes, which are running in the particular functional fields or across the functional fields. Further it's important to apply the methods for the decision-making process purposes, within the scope of the decision support systems [4].

The company management should represent the process of the effective treatment (management) relevant knowledge and information from the given company functional levels, which should cooperate at the in advance defined level - basis [5].

Enterprise information management system constitutes wholly important part of the successful company. Effective transmission, analysis, synthesis and the storing of the relevant data and information is the essential function of the enterprise information management systems. That fact can represent considerable competitive advantage, if it's respected the principle of the data - information effectivity and effectiveness [6]. 


\section{Logistics management}

The logistics management represents the one of the most important enterprise management fields. The effective management of the material flows in the internal and external company's supply chains is the area, where there are just applied the logistics management principles and methods. Thus, the logistics management plays the key role during enterprise strategies and plans creation - e.g. the issues, which are concerning with the required customer service setting, the suppliers relationships, manufacturing plants and warehouses locations, the distribution, inventory management or demand forecasting, and others [7].

The one of the requirements of the contemporary industrial or business markets, which is putting on the organizations, is the achievement of the high level responsiveness. Such requirement should be met at the lowest possible costs and the created added value should be on the other hand as the highest as possible. This matter of fact is the challenge to design new approaches or principles of the planning, management and control in the logistics management - the creation of the new methodologies or methodics [8].

\section{Methodology of integrated logistics management system creation}

The integrated logistics management system (ILMS) should be based, in up-to-dates companies, on the process management principles applied across particular enterprise functional fields. The design or the application of the ILMS should be realised continuously together with the actualisation or the implementation of the enterprise information system. The enterprise management system should have, in context of the enterprise management systems integration across the supply chains, a module for collaborative planning, forecasting and replenishment (CPFR) - as a foundation for other management modules.

ILMS should be designed for the management as the internal so the external material flows of the given company and that in context with the information and data gained with the CPFR module utilisation.

\subsection{Methodology of the integrated logistics management system design}

The methodology, which is still under development, is now composing by 5 methodics to design forecasting or logistics management sub-systems, as it is stated in the following points:

1. Methodics of independent demand forecasting sub-system design

2. Methodics of purchasing management sub-system design

3. Methodics of manufacturing management sub-system design

4. Methodics of distribution management sub-system design

5. Methodics of reverse material flow management sub-system design

Each of the above stated methodics can be further worked out into comprehensive methodology to design given forecasting or management information sub-system.

\subsection{Methodics to design independent demand forecasting sub-system}

The methodics or the steps succession, which are necessary to realise for design or for optimization of the enterprise forecasting sub-system, it's possible to sum up into 9 following points: 
1. an enterprise description or a description of its plants for which about to be created independent demand forecasting system (sales or consumption),

2. a supply chain visualization - internal and external parts,

3. the foundation of a point or the points of the supply chain dividing - the order penetration point theory,

4. an extensive portfolio segmentation of the accumulated material items - an inventory of e.g. the final products, semi-finished products or raw materials; in the order penetration point or points of the supply chain,

5. the analysis of the existing systems for independent demand forecasting,

6. a determination and statistical processing of the input data for demand forecasting (sales or consumption),

7. a basic analysis of demand pattern - a trend, a seasonality, an increase or a decrease,

8. a creation process of the most suitable models for independent demand forecasting of the particular material items segments - the inventory which is accumulated in the order penetration point of the supply chain; their application to forecast, [9]

9. a creation of CPFR module (collaborative planning forecasting and replenishment) for the purpose to integrate the company's forecasting system with the forecasting systems of the other companies, organizations or the retailers within the scope of given supply chains.

Above stated methodics of the independent demand forecasting system is universally applicable in any industry or in any tertiary sphere organization.

\subsection{Methodics to design purchasing logistics management sub-system}

The methodics to design purchasing logistics management sub-system, it's possible to sum up into 5 following points:

1. the current state analysis of the purchasing management system in the company,

2. a creation or an up-dating of the raw material or purchased items warehousing spaces layouts,

3. a creation of the particular management sub-systems:

a. data sub-system

b. forecasting sub-system

c. planning sub-system

d. inventory management sub-system

e. a selection and an evaluation suppliers sub-system, supply quantity determination

f. a setting particular logistics processes sub-system

g. personal sub-system

h. economic sub-system

ch. purchasing administration sub-system

i. control sub-system - a setting of performance measurements

j. sub-system of risk analysis and living environment protection,

4. an integration of created sub-systems,

5. a putting into operation $[10,11]$.

Stated methodics to design purchasing logistics management sub-system is universally applicable in any industry or tertiary sphere organization. 


\subsection{Methodics to design manufacturing logistics management sub-system}

The methodics to design manufacturing logistics management sub-system, it's possible, as well as the methodics regarding a purchasing, to sum up into 5 following points:

1. the current state analysis of the manufacturing management system in the company,

2. a creation or an up-dating of the manufacturing spaces layouts including associated warehouses,

3. a creation of the particular management sub-systems:
a. data sub-system
b. forecasting sub-system
c. planning sub-system
d. an optimal production batches determination sub-system
e. inventory management sub-system
f. a particular logistics processes determination sub-system
g. personal sub-system
h. economic sub-system
ch. manufacturing administration sub-system
i. control sub-system - a setting of performance measurements
j. sub-system of risk analysis and living environment protection
k. sub-system of maintenance planning and management,

4. an integration of created sub-systems,

5. a putting into operation. [12]

Stated methodics to design manufacturing logistics management sub-system is universally applicable in any industry or tertiary sphere organization, as well as 2 methodics briefly described above.

\subsection{Methodics to design distribution logistics management sub-system}

The methodics to design distribution logistics management sub-system, it's possible, as well as 3 previous methodics to sum up into 5 following points:

1. the current state analysis of the distribution management system in the company,

2. a creation or an up-dating of the distribution spaces layouts including associated warehouses,

3. a creation of the particular management sub-systems:
a. data sub-system
b. forecasting sub-system
c. planning sub-system
d. sub-system to vehicle full loading and an optimal transportation routes determination
e. inventory management sub-system
f. a setting of particular logistics processes sub-system
g. personal sub-system
h. economic sub-system
ch. distribution administration sub-system
i. control sub-system - a setting of performance measurements
j. sub-system of risk analysis and living environment protection
k. sub-system of fleet management (administration, planning and management),

4. an integration of created sub-systems, 
5. a putting into operation. [13]

The methodics to design distribution logistics management sub-system is universally applicable in any industry or tertiary sphere organization as the previous 3 methodics briefly described above.

\subsection{Methodics to design logistics management sub-system of the reverse material flows}

The methodics to design logistics management sub-system of reverse material flows, it's possible, as well as 4 previous methodics to briefly describe by the 5 following points:

1. the current state analysis of the reverse material flows management system in the company,

2. a creation or an up-dating of the warehouse layouts which are intended for reverse material flow items,

3. a creation of the particular management sub-systems:
a. data sub-system
b. forecasting sub-system
c. planning sub-system
d. sub-system to vehicle full loading and an optimal transportation routes determination
e. inventory management sub-system
f. a setting of particular logistics processes sub-system
g. personal sub-system
h. economic sub-system
ch. administration sub-system
i. control sub-system - a setting of performance measurements
j. sub-system of risk analysis and living environment protection
k. sub-system of fleet management (administration, planning and management)

4. an integration of created sub-systems,

5. a putting into operation $[10,11]$.

The methodics to design reverse material flows management sub-system is also universally applicable as the previous methodics in any industry or tertiary sphere organization.

\section{Conclusion}

The supply chains of given industrial branches are getting more and more complex and the material flows, which are streaming in them are getting more and more bulky $[14,15]$. Due to markets globalization, the industrial and business markets are getting also the markets more or less with commercial character. Thus, there are seeking out the new ways, as to gain or to retain the customers. The one of the way is to reduce the costs thru the progressive information enterprise management systems, and that within the scope of longterm socio-economic sustainability and living environment protection. These systems should meet the requirements of flexibility, stability, resilience and security with connection to contemporary supply chain development.

The important part of the information enterprise management systems is, in context of up-to-date supply chain development, the integrated logistics management system.

The article dealt with brief explanation of the essential notions: enterprise management, enterprise information management system and logistics management. The major article part has been the presentation of the created methodology to design integrated logistics 
management system, which has been created on the basis of former author's research. The methodology is universally applicable in any industry or organization of tertiary sphere. Thru methodology application, it's possible to create the integrated logistics management system in the practice - the management sub-systems of purchasing, manufacturing, distribution and reverse material flows.

The created methodology should contribute to the development of the issues regarding the enterprise information management systems in the theory and also in the practice. The article has presented new-fashioned approach of enterprise management with the emphasis on the effectivity and effectiveness connected with the planning, management and control of the internal and external company's or supply chain's material flows for which is the methodology also applicable.

This paper is supported by the research project "From horse-drawn railway to intermodal transport" within Visegrad Fund.

\section{References}

1. R.L. Tammineedi, Info. Sec. J. 19, 1, 36-50 (2010), DOI: 10.1080/19393550903551843

2. D. Malindzak, Proceedings of the 6th Carpathian Logistics Congress, 20-28 (Zakopane, Poland, 2016)

3. M. Kavan, Production and Operational Management, 424 p. (Prague: Grada, Czech Republic, 2002)

4. W.M.P. van der Aalst, A.H.M. ter Hofstede, M. Weske, Lect. Not. in Com. Sci. 2678, 1-12 (2003), DOI: 10.1007/3-540-44895-0_1

5. T.S. Raghu, A. Vinze, Dec. Sup. Sys. 43, 3, 1062-1079 (2007)

6. S. Salah, A. Rahim, \& J. A. Carretero, Inter. Jour. of Bus. Exc. 6, 2, 161-191 (2013), DOI: 10.1504/IJBEX.2013.052478

7. J. Gattorna, A. Day, J. Hargreaves, Log. Inf. Man., 4, 2, 2-86 (1991), DOI: $10.1108 / 09576059110143603$

8. F. Nilsson, The Inter. J. of Log. Man. 17, 1, 38-54 (2006), DOI: 10.1108/09574090610663428

9. M. Hart, The Approaches to Independent Demand Forecasting in an Industrial Company, 203 p. (Dissertation Thesis, VŠB-TU Ostrava, Czech Republic, 2010)

10. M. Hart, P. Taraba, J. Konecny, Proceedings of the 5th Carpathian Logistics Congress, 110-115 (Priessnitz Spa, Jeseník, Czech Republic, 2015)

11. M. Hart, P. Taraba, M. Tomastik, Proceedings of the 6th Carpathian Logistics Congress, 99-104 (Zakopane, Poland, 2016)

12. M. Hart, P. Taraba, J. Konecny, Proceedings of the 3rd International Conference on Sustainable Design and Manufacturing, 191-202 (Chania, Crete, Greece, 2016)

13. M. Hart, P. Taraba, M. Tomastik, Proceedings of the 28th Annual Nordic Logistics Research Network Conference (Turku, Finland, 2016)

14. P. Kacmary, D. Malindzak, Ac. Mon. Slo. 15, 1, 53-60 (2010)

15. P. Kacmary, J. Saderova, A. Rosova, M. Straka, App. Me. and Mat. 683, 61-65. (2014), DOI: 10.4028/www.scientific.net/AMM.683.61 